\title{
Development and optimization of a method for the analysis of low-molecular-mass organic acids in plants by capillary electrophoresis with indirect UV detection
}

\author{
Min Wang, Feng Qu, Xiao-Quan Shan, Jin-Ming Lin* \\ Research Center for Eco-Environmental Sciences, Chinese Academy of Sciences, P.O. Box 2871, Beijing 100085, China
}

Received 29 July 2002; received in revised form 16 December 2002; accepted 31 December 2002

\begin{abstract}
Capillary zone electrophoresis was developed to analyze low-molecular-mass organic acids including oxalic, tartaric, formic, malic, citric, succinic, glutaric, acetic and lactic acid. The influences of some crucial parameters such as buffer concentration, $\mathrm{pH}$ value, surfactant concentration and separation temperature, on electrophoretic separation were investigated. Under the conditions of $15 \mathrm{~m} M$ phthalate containing $0.6 \mathrm{~m} M$ tetradecyltrimethylammonium bromide as the run buffer (pH 5.6); separation voltage $-15 \mathrm{kV}(-263.2 \mathrm{~V} / \mathrm{cm})$ and temperature $25^{\circ} \mathrm{C}$, a satisfactory separation of nine organic acids was accomplished within $7 \mathrm{~min}$. The detection limits $(S / N=3)$ ranged from 0.008 to $0.08 \mu \mathrm{g} / \mathrm{ml}$ and the quantification limits ranged from 0.01 to $0.1 \mu \mathrm{g} / \mathrm{ml}$ for electrokinetic injection. The method was successfully applied to analyze organic acids in different parts of Var splendens (an edible vegetable in China). The recoveries of organic acids in real samples ranged from 88 to $121 \%$.
\end{abstract}

(C) 2003 Elsevier Science B.V. All rights reserved.

Keywords: Plant materials; Var splendens; Organic acids

\section{Introduction}

Low-molecular-mass (LMM) organic acids are common and natural constituents in many plants. Analysis of these organic acids has become increasingly important due to their role in the physiological activity of plants. Some organic acids such as citric, malic, succinic and oxalic acid are parts of Krebs cyclic pathway. They are intermediates in the most

\footnotetext{
*Corresponding author. Tel.: +86-106-284-1953; fax: +86106-284-1953.

E-mail address: jmlin@mail.rcees.ac.cn (J.-M. Lin).
}

important metabolic pathway of carbohydrates, lipids and proteins [1]. Many of them are believed to play an important role in the cation transport, either nutrient or toxic, in xylem vessels. In addition, these organic acids respond to environment stimuli such as photoperiod, temperature, water and nutrition supply. For example, LMM organic acids in root exudation, mainly including acetic, aconitic, citric, formic, glycolic, lactic, malic, oxalic and succinic acids, are enhanced in many plant species under phosphorus deficiency [2]. Moreover, these acids in root exudates are related with the mobilization of soil mineral nutrients, e.g. nickel, aluminum, iron, zinc, copper 
and manganese [3-5]. The accumulation of organic acids in root cell compartments of metal tolerant plant species may indicate a more general character of the metal organic acid interrelationships in plants [6]. The success in clarification of these functions depends on the identification of organic acids in soil and different parts of plants.

For the simultaneous determination of organic acids in plant samples, many separation methods have been developed. As LMM organic acids are generally non-volatile, their determinations with gas chromatography (GC) require derivatisation. However, the derivatisation process is often quite tedious, time-consuming and retards the reproducibility of the analysis [7]. Currently, the most widely used methods for the determination of LMM organic acids in biological samples include high-performance liquid chromatography (HPLC) $[8,9]$ and ion chromatography (IC) $[10,11]$. Both of these methods are not without limitations. For example, these two methods need large quantity elutant. Furthermore, organic substances in the plant matrix need to be removed by sample preparation assay limited column lifetime or complicated chromatogram may result. In addition, with both HPLC and IC, very little can be done to manipulate the selectivity as the analytical columns are only used with simple buffers or dilute acid. Therefore, it is difficult to optimize the separation for specific analysis from specific matrices.

Recently, capillary electrophoresis (CE) has complementary to chromatographic methods; due to providing several promising features like high separation efficiency, fast analysis and low consumption of chemicals. It has been widely used in the determination of LMM organic acids in food [12-16] and environmental samples [17,18]. In CE method, these acids are frequently migrated as anions in a co-electroosmotic mode with indirect UV detection. Generally, an electroosmotic flow modifier like tetradecyltrimethylammonium bromide is added to the run buffer in order to reverse the electroosmotic flow (EOF). Also compounds with UV-absorbing properties must be added in the run buffer to provide suitable conditions for indirect UV detection. Doble et al. [19] discuss several separation factors, including nature of the probe, the relative mobility of the probe and the analyte, the EOF modifier and the type of buffer, in CE of inorganic and LMM organic anions using indirect UV detection. Moreover, the separation selectivity could be enhanced by adding divalent cations to the run buffer [20,21].

The purpose of this paper is to develop and optimize a suitable CE method in analysis of LMM organic acids in plant samples. We discuss the influences of several crucial parameters, including buffer concentration, $\mathrm{pH}$ value, type and concentration of surfactant and temperature. The applicability of the method is demonstrated by analysis of these acids in different parts of Var splendens (an edible vegetable in China), e.g. root, stem and leaf.

\section{Experimental}

\subsection{Instrumentation}

All experiments were performed on a Beckman P/ACE MDQ capillary electrophoresis system (Beckman, Fullerton, CA, USA) equipped with a photodiode array detection system. The electropherograms were recorded and integrated by an IBM personal computer with 32 Karat software version 4.0 (Beckman). A fused-silica capillary (Beckman) with a total length of $57 \mathrm{~cm}$ and an I.D. of $75 \mu \mathrm{m}$ was used. A detection window was created at $50 \mathrm{~cm}$ from the capillary inlet by removing the polyimide coating. Indirect UV detection was performed at a single wavelength of $254 \mathrm{~nm}$. The hydrostatic injection mode (5 s, 20 p.s.i.) or the electrokinetic injection mode $(20 \mathrm{~s},-5 \mathrm{kV})$ was used for the injection of the standard solution or plant sample, respectively $(1$ p.s.i. $=6894.76 \mathrm{~Pa})$.

\subsection{Chemicals}

All organic acids, including oxalic, tartaric, formic, malic, citric, acetic, lactic, glutaric and succinic acids were from Beijing Reagents (China). Potassium hydrogenphthalate was obtained from Shanghai Reagent Factory (China). Dodecyltrimethylammonium bromide (DTAB), tetradecyltrimethylammonium bromide (TTAB), hexadecyltrimethylammonium bromide $(\mathrm{CTAB})$ and octadecyltrimethylammonium chloride (OTAC) were purchased from Kanto Chemicals (Tokyo, Japan). All reagents were of analytical-reagent grade. Acetone was also from 
Beijing Reagents and used as marker for the determination of electroosmotic flow. Water for preparation of sample and buffer solution was deionized by a Milli-Q purification system with a $0.2-\mu \mathrm{m}$ fiber filter (Barnstead, CA, USA).

\subsection{Procedure}

Var splendens, which is a common vegetable in China, was purchased from the market. Root, stem and leaf were detached and smashed. A 10-g sample material was weighted and placed into a 50-ml beaker, adding $10 \mathrm{ml}$ deionized water, incubating and homogenizing for $30 \mathrm{~min}$ on water-bath at about $50{ }^{\circ} \mathrm{C}$. After cooling, the slurry was transferred quantitatively into a $25-\mathrm{ml}$ volumetric flask. Finally, the samples were divided into small parts that were kept in a refrigerator. Before injection into the $\mathrm{CE}$ system, the samples were filtered through a $0.2-\mu \mathrm{m}$ syringe filter.

New capillary were initially washed with methanol for $5 \mathrm{~min}$, followed by deionized water for $2 \mathrm{~min}$, $0.1 \mathrm{M} \mathrm{HCl}$ for $5 \mathrm{~min}$, deionized water for $2 \mathrm{~min}$, $0.1 M \mathrm{NaOH}$ for $5 \mathrm{~min}$ and deionized water for $2 \mathrm{~min}$. To achieve reproducible, all experiments were performed at $25^{\circ} \mathrm{C}$ and were run in triplicate. Before each separation, the capillary was rinsed with $0.1 \mathrm{M}$ $\mathrm{NaOH}$ for 2 min, deionized water for 2 min and run buffer for $2 \mathrm{~min}$.

Electropherograms were obtained with a phthalate buffer, preparing with deionized water and adjusted to the appropriate $\mathrm{pH}$ with $0.1 M$ sodium hydroxide. Also, $0.6 \mathrm{~m} M$ TTAB was added, resulting in a reversed electroosmotic flow and necessitating the use of a reversed-polarity source. Stock solutions of organic acids were obtained by dissolving the organic acid in deionized water, and the concentration of all stock organic acid solution were $500 \mu \mathrm{g} / \mathrm{ml}$. Standard solutions were prepared by dilution of stock solutions.

\subsection{Calculation}

Electroosmotic mobility, $\mu_{\mathrm{eo}}$, was determined by the measurement of the migration time of $5 \%$ acetone solution, $t_{\mathrm{eo}}$, according to the following expression:
$\mu_{\mathrm{eo}}=\left(L_{\mathrm{t}} L_{\mathrm{d}}\right) /\left(V t_{\mathrm{eo}}\right)$

where $L_{\mathrm{t}}$ is the total capillary length, $L_{\mathrm{d}}$ is the capillary length from injection inlet to the detector and $V$ is the applied voltage.

Similarly, the observed mobility of organic acids, $\mu_{\mathrm{obs}}$, was calculated from the migration time of the organic acids, $t$, according to the following relation:

$\mu_{\mathrm{obs}}=\left(L_{\mathrm{t}} L_{\mathrm{d}}\right) /(V t)$

The electrophoretic mobility, $\mu_{\mathrm{ep}}$, equal to the difference of $\mu_{\mathrm{eo}}$ and $\mu_{\mathrm{obs}}$ :

$\mu_{\mathrm{ep}}=\mu_{\mathrm{obs}}-\mu_{\mathrm{eo}}$

The electroosmotic and electrophoretic mobilities were directed towards the anode and considered as positive values.

\section{Results and discussion}

\subsection{Effect of electrophoretic run buffer concentration}

Eqs. (1) and (2) predicted that electroosmotic mobility $\left(\mu_{\mathrm{eo}}\right)$ and electrophoretic mobility $\left(\mu_{\mathrm{ep}}\right)$ on a bare capillary decreased with increasing electrophoretic run buffer concentration:

$\mu_{\mathrm{eo}}=\frac{\varepsilon_{0} \varepsilon_{r} \zeta}{\eta}$

$\mu_{\mathrm{ep}}=\frac{2}{3} \cdot \frac{\varepsilon_{0} \varepsilon_{\mathrm{r}} \zeta}{\eta}$

where $\eta$ is the viscosity, $\zeta$ the zeta potential, $\varepsilon_{\mathrm{r}}$ the dielectric constant, and $\varepsilon_{0}$ the permittivity of vacuum $\left(8.85 \cdot 10^{-12} \mathrm{C}^{2} \mathrm{~N}^{-1} \mathrm{~m}^{-2}\right)$ [22]. But in reversed flow, the mechanism was more complex as higher run buffer concentrations increased the adsorption of TTAB onto the capillary wall [23]. The influence of electrophoretic run buffer concentration on EOF was investigated using acetone as a $\mu_{\text {eo }}$ marker. $\mu_{\text {eo }}$ decreased with increasing the concentration of electrophoretic run buffer. Its result indicated the shrinking of electric double layer dominated over the increased TTAB adsorption. The electrophoretic mobility $\left(\mu_{\mathrm{ep}}\right)$ was also reduced as a function of the electrophoretic run buffer concentration for each of 
the organic acids, which result from decreased $\zeta$ and higher buffer conductivity. When applying voltage, the high conductivity resulted in a lower electric field. Then sample ions would move slower than those in the low concentration buffer. As co-electroosmotic mode was used, the observed electrophoretic mobility ( $\mu_{\mathrm{obs}}$ ) was given by the sum of $\mu_{\mathrm{eo}}$ and $\mu_{\mathrm{ep}}$. The migration time was proportional to concentration. When the electrophoretic run buffer was $5 \mathrm{mM}$, the resolution between malic acid and citric acid was very low. Increasing the electrophoretic run buffer concentration improved the separation of organic acids, but at the expense of longer run times. The baseline separation of malic acid and citric acid could be achieved at $15 \mathrm{mM}$. Although resolution was little enhanced at $20 \mathrm{mM}$, the optimal electrophoretic run buffer concentration chosen was $15 \mathrm{~m} M$, due to the shorter migration times at this concentration.

\subsection{Effect of electrophoretic run buffer $p H$}

The $\mathrm{pH}$ of the electrophoretic run buffer must be carefully controlled, as it not only influenced the EOF, but also the electrolytic dissociation equilibrium of organic acids, ultimately affecting resolution. The cationic surfactant (TTAB) was added in the run buffer and then bound to the capillary surface, resulting in positive charge density and reverse EOF. As the electrophoretic run buffer $\mathrm{pH}$ was increased, more $\mathrm{Si}-\mathrm{OH}$ groups were ionized with no concomitant increase in TTAB binding because of surface saturation. As a result, the net surface charge density turned more and more negative and the EOF decreased as the $\mathrm{pH}$ of electrophoretic run buffer increased [24]. On the other hand, the increase of ionic strength caused by $\mathrm{pH}$ increase also reduced EOF (Fig. 1). The influence of $\mathrm{pH}$ on electrophoretic mobility of organic acids was also shown on Fig. 1. The migration time prolonged as increasing of $\mathrm{pH}$, with changing the elution order of citric acid. At $\mathrm{pH}$ lower than 6.0, the organic acids present different ionization degrees, they have two to three ionization constants with $\mathrm{p} K_{\mathrm{a}}$ values $3.1 ; 4.8 ; 6.4$ for citric acid, 3.46; 5.10 for malic acid, 3.22; 4.81 for tartaric acid [25]. According to CE methods, the separation of organic acids was achieved corresponding with their charge to mass ratio. So elution order was tartaric,

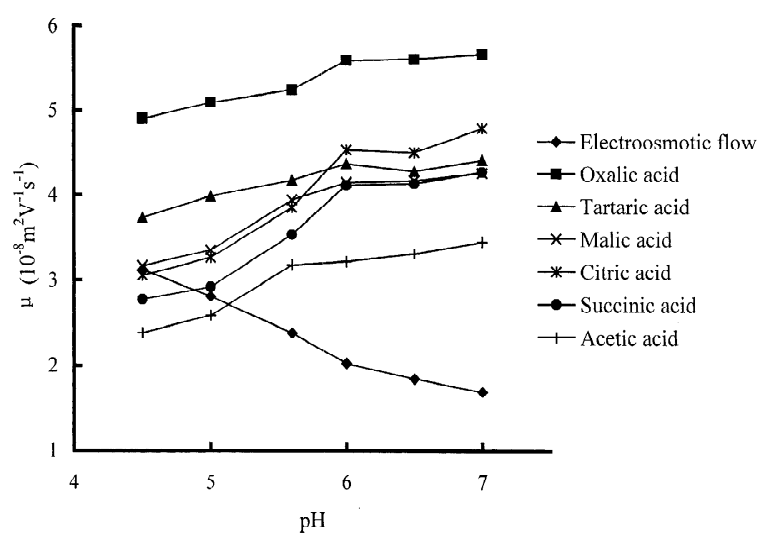

Fig. 1. Effect of $\mathrm{pH}$ on the mobility. Conditions: fused-silica capillary, $57 \mathrm{~cm}$ (length to detector $50 \mathrm{~cm}$ ); buffer $15 \mathrm{mM}$ phthalate containing $0.4 \mathrm{~m} M$ TTAB; voltage: $-15 \mathrm{kV}$; detection $254 \mathrm{~nm}$; temperature $25^{\circ} \mathrm{C}$; hydrodynamic injection 20 p.s.i. for $5 \mathrm{~s}$.

malic and citric acid, and a good resolution can be attained when $\mathrm{pH}$ value was 5.6. The tricarboxylic citric acid ionized at higher $\mathrm{pH}$, which increased its charge. Therefore, citric acid migrated faster than tartaric and malic acid as shown in Fig. 1.

\subsection{Effect of surfactant}

Four surfactants, DTAB, TTAB, CTAB and OTAC, were investigated. The effects of different surfactants on $\mu_{\text {eo }}$ were illustrated in Table 1 . Electroosmotic flow towards the anode was considered as positive values. With exception of DTAB, the others can successfully reverse the EOF and had similar $\mu_{\mathrm{eo}}$, which resulted from the saturation of the capillary walls with the surfactant at $0.4 \mathrm{mM}$. For three other surfactants, the similar resolutions were obtained, and the solubility decreased with increas-

Table 1

Electroosmotic mobility, $\mu_{\mathrm{eo}}$, employed different surfactants

\begin{tabular}{lllll}
\hline & DTAB & TTAB & CTAB & OTAC \\
\hline$\mu_{\text {eо }}\left(10^{-8} \mathrm{~m}^{2} \mathrm{~V}^{-1} \mathrm{~s}^{-1}\right)$ & -3.61 & 2.53 & 2.55 & 2.57 \\
\hline
\end{tabular}

Conditions: buffer: $15 \mathrm{mM}$ phthalate- $0.4 \mathrm{mM}$ surfactant (pH 5.6), other conditions as in Fig. 1

Electroosmotic flow towards the anode was considered as positive values and that towards the cathode was considered as negative values. 
ing of hydrophobic carbon chain. So TTAB was selected as the best surfactant.

The separation of organic acids was little affected by the concentration of TTAB. The electroosmotic mobility increased when varying the TTAB concentration from 0.2 to $0.4 \mathrm{~m} M$, and it remained constant for higher TTAB concentration. For the capillary walls were saturated, free surfactant cations increased with increase in surfactant concentration, which potentially bind to the organic acid molecule, changing its net charge and thus its electrophoretic mobility. The best concentration $(0.6 \mathrm{mM})$ was chosen, since the sensitivity was reduced when the concentration was too high.

\subsection{Effect of separation temperature}

The temperature significantly affected the migration times of organic acids. A remarkable decrease of migration time for increasing temperature from 15 to $35^{\circ} \mathrm{C}$ has been recorded. These decreases were primarily due to the viscosity that was related to the temperature. Although higher temperature is to shorten the analysis time, the resolution reduced because of higher Joule heating. Therefore, the optimal temperature necessary to attain the highest level of resolution and shortest analysis time was concluded to be $25^{\circ} \mathrm{C}$.

\subsection{Quantification}

As shown in Table 2, calibration curve for each acid was established from six concentration levels of the mixing sample, which showed linearity within two orders of magnitude between peak area and sample concentration. In order to improve the limit of detection (LOD), electrokinetic injection was applied. Compared with hydrodynamic injection, electrokinetic injection gave worse linearity because the electric field being influenced by the sample conductivity affected the calibration curve. While difficult in practice to employ quantitatively, electrokinetic injection can provide impressive trace enrichment. Thus, electrokinetic injection was suitable for analysing trace organic acids in plant. The relative standard deviation (RSD) of the peak area was calculated based on five duplicate injections of a standard sample. The LOD were obtained at a 3:1 signal-to-noise ratio. The high reproducibility and low LOD indicated that the method was reliable for analyzing organic acids.

\subsection{Application to real samples}

The method was used to determine the organic acids in root, stem and leaf of Var splendens. Typical electropherograms were shown in Fig. 2. Nine organic acids can be well separated without the interference of inorganic ions (Fig. 2I). A remarkable difference of organic acids content in three parts was observed. The migration times of organic acids in real samples increased because a great deal of ions in samples influence the separation (Fig. 2III). The reproducibility of migration time was very good; the relative standard deviation for triplicate, successive analyses was less than $0.6 \%$ (Table 3 ).

Table 2

Quantification data (conditions as in Fig. 2)

\begin{tabular}{|c|c|c|c|c|c|c|}
\hline $\begin{array}{l}\text { Organic } \\
\text { acid }\end{array}$ & $a$ & $b$ & $r$ & $\begin{array}{l}\text { Linear range } \\
(\mu \mathrm{g} / \mathrm{ml})\end{array}$ & $\begin{array}{l}\operatorname{RSD}(\%) \\
(n=5)\end{array}$ & $\begin{array}{l}\text { LOD } \\
(\mu \mathrm{g} / \mathrm{ml})\end{array}$ \\
\hline Formic & 28864 & 410.01 & 0.9987 & $0.02-1.0$ & 0.78 & 0.01 \\
\hline Tartaric & 15262 & 146.14 & 0.9991 & $0.01-1.0$ & 0.82 & 0.008 \\
\hline Malic & 15619 & 293.60 & 0.9990 & $0.02-1.0$ & 0.48 & 0.01 \\
\hline Citric & 8347 & 841.10 & 0.9974 & $0.10-1.0$ & 0.11 & 0.08 \\
\hline Succinic & 18740 & 370.07 & 0.9992 & $0.02-1.0$ & 0.55 & 0.01 \\
\hline Acetic & 23717 & 572.97 & 0.9993 & $0.02-1.0$ & 0.96 & 0.01 \\
\hline Glutaric & 21397 & -987.71 & 0.9957 & $0.05-1.0$ & 0.43 & 0.03 \\
\hline Lactic & 21694 & 323.93 & 0.9971 & $0.02-0.5$ & 1.04 & 0.01 \\
\hline
\end{tabular}

Calibration curves are expressed as regression lines $(y=a x+b)$, where $y$ is integrated peak area and $x$ is concentration of organic acid $(\mu \mathrm{g} / \mathrm{ml}) . a$ is slope, $b$ is intercept and $r$ is relative coefficient. RSD is relative standard deviation. LOD is limit of detection at 3:1 signal-to-noise ratio. 

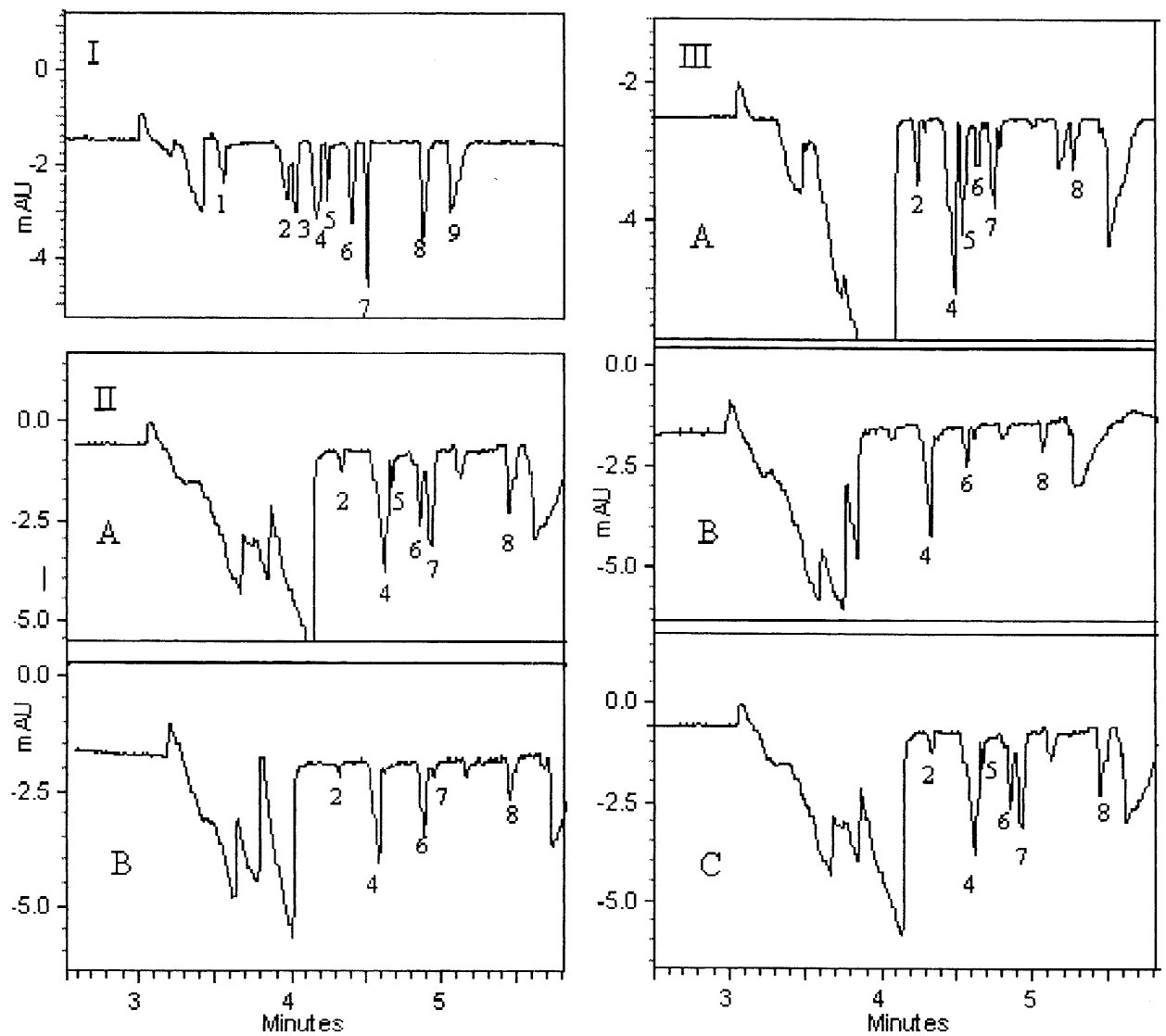

Fig. 2. Electropherograms of nine organic acids. Conditions: fused-silica capillary, $57 \mathrm{~cm}$ (length to detector $50 \mathrm{~cm}$ ); buffer $15 \mathrm{~m} M$ phthalate, $0.6 \mathrm{~m} M$ TTAB, pH 5.6; separation voltage: $-15 \mathrm{kV}$; detection $254 \mathrm{~nm}$; temperature $25^{\circ} \mathrm{C}$; electrokinetic injection $20 \mathrm{~s}, V_{\text {inj }}=-5$ $\mathrm{kV}$. (I) Electropherogram of standard sample. (II) Electropherograms of organic acids in Var splendens leaf for storage several days. (A) The fresh sample. (B) Storage for 2 days (storage temperature $<0{ }^{\circ} \mathrm{C}$ ). (III) Electropherograms of organic acids in different parts of Var splendens. (A) Root. (B) Stem. (C) Leaf. Peaks: $1=$ oxalic acid, $2=$ formic acid, $3=$ tartaric acid, $4=$ malic acid, $5=$ citric acid, $6=$ succinic acid, $7=$ glutaric acid, $8=$ acetic acid, $9=$ lactic acid.

However, the organic acid contents were reduced during storage. For example, after storage for 2 days, the contents of formic, malic, succinic, glutaric, acetic acids in leaf were reduced to $0.02,0.82,0.36$, $0.09,0.11 \mu \mathrm{g} / \mathrm{g}$, respectively, and that of citric acid was lower than the LOD. The unreliability of organic acids determinations was related to sample instability, not to the analytical method (Fig. 2II). In fact, some of the soil microorganisms, or their associated enzymatic activity can survive during the sample preparation process. Many aerobic microorganisms can break-down LMM organic acids in their anabol- ism. Furthermore, the survived enzyme, such as succinic dehydrogenase, malic enzyme, which widely existed in most plants and plays a very important role in the Krebs cycle, also can decomposed these acids. The key step in achieving good performance was to analyse three times immediately after sample preparation because longtime storage made sample have ample time to develop enzymatic activity. Typical results for six organic acid determinations were summarized in Table 3. The recoveries of formic and citric acid were not good enough, due to their low contents and decomposition. 
Table 3

Result for the determination of organic acids in Var splendens by CE (conditions as in Fig. 2)

\begin{tabular}{|c|c|c|c|c|c|c|c|}
\hline Sample & & Formic & Malic & Citric & Succinic & Glutaric & Acetic \\
\hline \multirow[t]{5}{*}{ Root } & $t_{\mathrm{R}}($ mean, $\min )$ & 4.263 & 4.506 & 4.564 & 4.658 & 4.767 & 5.292 \\
\hline & $t_{\mathrm{R}}$ repeatability $(\mathrm{RSD}, \%)$ & 0.39 & 0.28 & 0.37 & 0.25 & 0.31 & 0.28 \\
\hline & Content $(\mu \mathrm{g} / \mathrm{g})$ & 0.15 & 1.44 & 1.49 & 0.06 & 0.37 & 0.20 \\
\hline & Recovery (\%) & 107 & 105 & 105 & 116 & 95 & 110 \\
\hline & $\operatorname{RSD}(\%)$ & 3.8 & 2.1 & 3.7 & 4.2 & 1.8 & 3.6 \\
\hline \multirow[t]{5}{*}{ Stem } & $t_{\mathrm{R}}($ mean, min $)$ & N.D. & 4.345 & N.D. & 4.578 & N.D. & 5.085 \\
\hline & $t_{\mathrm{R}}$ repeatability $(\mathrm{RSD}, \%)$ & - & 0.14 & - & 0.13 & - & 0.18 \\
\hline & Content $(\mu \mathrm{g} / \mathrm{g})$ & - & 1.24 & - & 0.12 & - & 0.09 \\
\hline & Recovery (\%) & - & 98 & - & 121 & - & 109 \\
\hline & $\operatorname{RSD}(\%)$ & - & 1.8 & - & 4.4 & - & 2.4 \\
\hline \multirow[t]{5}{*}{ Leaf } & $t_{\mathrm{R}}(\operatorname{mean}, \min )$ & 4.339 & 4.610 & 4.659 & 4.842 & 4.920 & 5.433 \\
\hline & $t_{\mathrm{R}}$ repeatability $(\mathrm{RSD}, \%)$ & 0.36 & 0.56 & 0.45 & 0.49 & 0.33 & 0.56 \\
\hline & Content $(\mu \mathrm{g} / \mathrm{g})$ & 0.06 & 1.43 & 0.28 & 0.42 & 0.66 & 0.54 \\
\hline & Recovery (\%) & 113 & 107 & 95 & 88 & 105 & 94 \\
\hline & $\operatorname{RSD}(\%)$ & 2.6 & 1.4 & 2.4 & 3.1 & 2.0 & 2.9 \\
\hline
\end{tabular}

$t_{\mathrm{R}}:$ migration time.

N.D.: no detectable amount.

RSD: relative standard deviation.

\section{Conclusion}

The analysis of organic acids in different plant parts with $\mathrm{CE}$ is a difficult task due to their low contents and unstable samples. This method quantified six organic acids, including formic, malic, citric, succinic, glutaric and acetic acids in Var splendens, and it is simple, rapid and does not require any complicated sample preparation. When using electrokinetic injection, the limits of determination are lower than the relevant concentrations of these acids in plant extracts. Hence, this method is suitable for quick determination of organic acids in plant samples.

\section{Acknowledgements}

The authors wish to thank the financial supports from National Science Fund for Distinguished Young Scholars of China (No. 20125514), National Natural Science Foundation of China (No. 20275043) and the National High Technology Research and Development Program of China (863 Program) (No. 2001AA630503).

\section{References}

[1] T.A. Bennet-Clark, The role of the organic acids in plant metabolism. Part I, New Phytol. 32 (1993) 37.

[2] F.S. Zhang, J. Ma, Y.P. Cao, Plant Soil 196 (1997) 261.

[3] X.E. Yang, V.C. Baligar, J.C. Foster, D.C. Manens, Plant Soil 196 (1997) 271.

[4] D.L. Jones, L.V. Kochian, Plant Soil 182 (1996) 221.

[5] J.F. Loneragan, Plant Soil 196 (1997) 163.

[6] M.H.M.N. Senden, A.J.G.M. Van der Meer, T.G. Verburg, H.Th. Wolterbeek, Plant Soil 171 (1995) 333.

[7] M. Morval, I. Molnar-Perl, D. Knausz, J. Chromatogr. 552 (1991) 337.

[8] D. Zielinska, I. Poels, M. Pietraszkiwicz, J. Radecki, H.J. Geise, L.J. Nagels, J. Chromatogr. A 915 (2001) 25.

[9] E. Tatár, V.G. Mihucz, B. Kmethy, G. Zárary, F. Fodor, Microchem. J. 67 (2000) 73.

[10] R. Gabriel, J. Kesselmeier, Plant Cell Physiol. 40 (1999) 604.

[11] J. Qiu, X. Jin, J. Chromatogr. A 950 (2002) 81.

[12] B.F. Kenney, J. Chromatogr. 546 (1991) 423.

[13] L. Saavedra, A. García, C. Barbas, J. Chromatogr. A 881 (2000) 395.

[14] H. Horie, Y. Yamauchi, K. Kohata, J. Chromatogr. A 817 (1998) 139.

[15] P. Kuban, B. Karlerg, Anal. Chem. 61 (1989) 766.

[16] T. Soga, G.A. Ross, J. Chromatogr. A 837 (1999) 231.

[17] J. Hagberg, J. Dahlén, S. Karlsson, B. Allard, Int. J. Environ. Anal. Chem. 78 (2000) 385. 
[18] A. Levart, M. Guèek, B. Pihlar, M. Veber, Chromatographia (Suppl.) 51 (2000) 321.

[19] P. Doble, M. Macka, P.R. Haddad, Trends Anal. Chem. 19 (2000) 10.

[20] M. Chiari, N. Dell'Orto, L. Casella, J. Chromatogr. A 745 (1996) 93.

[21] M. Chiari, J. Chromatogr. A 805 (1998) 1.
[22] J. Knox, J. Chromatogr. A 680 (1994) 3.

[23] C.A. Lucy, R.S. Underhill, Anal. Chem. 68 (1996) 300.

[24] G.M. Janini, K.C. Chan, J.A. Barnes, G.M. Muschik, H.J. Issaq, J. Chromatogr. A 653 (1993) 321.

[25] T. Zhou, R. Wang, W. Lu (Eds.), Handbook of Analytical Chemistry, Chemical Industry Press, Beijing, 1997, p. 108, Part I. 